\title{
O paradoxo em Kierkegaard e o irracional em Otto
}

\author{
The paradox in Kierkegaard and the irrational in Otto
}

Humberto Araujo Quaglio de Souza*

\begin{abstract}
Resumo
Søren Kierkegaard e Rudolf Otto são dois autores religiosos tradicionalmente associados a um modo de pensar que reconhece os limites do uso da razão para o ser humano. No pensamento kierkegaardiano, o Paradoxo Absoluto é uma das ideais mais emblemáticas desse reconhecimento de limites para a racionalidade. No pensamento de Otto, por sua vez, o irracional, em sua contraposição ao racional, é um dos elementos mais importantes em suas reflexões sobre a natureza da própria religião. Este artigo apresenta algumas considerações sobre as possibilidades de comparação entre esses conceitos fundamentais nas obras do filósofo dinamarquês e do teólogo alemão.
\end{abstract}

Palavras-chave

Kierkegaard. Otto. Paradoxo. Irracional.

\begin{abstract}
Søren Kierkegaard and Rudolf Otto are two religious authors traditionally related to a way of thinking that acknowledges the limitations of the use of reason for the human being. In the Kierkegaardian thought the Absolute Paradox is one of the most emblematic ideias of this acknowledgement of the limitations of the rationality. In Otto's thought, on its turn, the irrational, in its contraposition to the rational, is one of the most important elements in his reflections about the very nature of religion. This paper presents some considerations about the possibilities of comparison between these fundamental concepts in the works of the Danish philosopher and of the German theologian.
\end{abstract}

Keywords

Kierkegaard. Otto. Paradox. Irrational.

\section{Introdução}

O paradoxo, e mais especificamente a ideia de Paradoxo Absoluto, é um dos grandes objetos de reflexão para aqueles que se dedicam ao estudo do pensamento de

[Texto recebido em junho de 2018 e aceito em junho de 2018, com base na avaliação cega por pares realizada por pareceristas ad hoc]

* Professor Adjunto no Departamento de Ciência da Religião (Universidade Federal de Juiz de Fora). Doutor em Ciência da Religião (Universidade Federal de Juiz de Fora). E-mail: hquaglio@terra.com.br 
Søren Kierkegaard, e especialmente às pesquisas relacionadas às obras Migalhas Filosóficas, de 1844, e Pós-escrito às Migalhas Filosóficas, de 1846, que o filósofo de Copenhague publicou sob o pseudônimo Johannes Climacus. Para aqueles que se dedicam ao estudo do pensamento de Rudolf Otto, a ideia de irracional, especialmente como exposta em sua obra mais conhecida, O Sagrado, de 1917, tem importância similar à da ideia de paradoxo no campo das pesquisas kierkegaardianas. Estudos anteriores já empreenderam investigações comparando a obra e o pensamento desses dois teólogos ligados à tradição protestante. ${ }^{1} \mathrm{O}$ presente artigo pretende seguir essa mesma linha de investigação dando, porém, especial atenção a esses dois grandes temas presentes na obra do teólogo alemão e do escritor dinamarquês.

Kierkegaard e Otto são autores sujeitos a uma espécie de crítica advinda tipicamente de leituras apressadas e superficiais de suas obras. Por lidarem com questões fortemente relacionadas aos limites da racionalidade, o dinamarquês e o alemão estão sujeitos a serem (mal) compreendidos como promotores de irracionalismo, de subjetivismo ou mesmo de relativismo. Em tais críticas, que são irrefletidas como se pretenderá argumentar aqui, estarão presentes considerações apressadas justamente sobre o uso de termos como paradoxo e irracional. Contudo, é possível encontrar tais tipos de crítica até entre aqueles que se dedicam mais detidamente a compreender esses dois pensadores tão significativos para o estudo da religião, especialmente no caso de Kierkegaard.

Poderiam então os dois conceitos, o paradoxo kierkegaardiano e o irracional ottoniano, serem considerados em um exame comparativo tão somente por evocarem uma ideia que evoca uma contraposição à razão? Ou haveria entre eles uma afinidade de conteúdo (ainda que parcial) que permitiria a aplicabilidade de ambos à análise de questões do mesmo tipo na filosofia, na teologia e na ciência da religião? E o mais importante: é correto dizer que Otto e Kierkegaard são, por conta dessas suas ideias, propositores de algum tipo de irracionalismo que remete à absurdidade e à abolição da própria ideia de racionalidade. Para enfrentar esses problemas, é conveniente expor desde o início algumas considerações sobre ambos os termos em seus respectivos contextos históricos e culturais.

\section{O paradoxo kierkegaardiano}

No campo dos estudos da obra de Kierkegaard, muito se tem escrito sobre a ideia de Paradoxo Absoluto que o pensador dinamarquês expôs em sua obra Migalhas filosóficas, publicada em 1844 sob o pseudônimo Johannes Climacus. Kierkegaard é considerado, de modo bastante adequado, um exemplo de pensador em cujas obras é facilmente

1 Cf. QUAGLIO DE SOUZA, Humberto Araujo. Fenomenologia da experiência religiosa em Kierkegaard e Rudolf Otto. São Paulo: Liber Ars, 2014; QUAGLIO DE SOUZA, Humberto Araujo. Kierkegaard sob a perspectiva de Otto: o instante e o numinoso. Revista Pandora Brasil, n. 23, p. 25-36, out. 2010. 
perceptível a pressuposição de que a capacidade humana de fazer uso da razão é limitada. E é até mesmo possível defender a ideia de que na referida obra de 1844 tal aspecto de seu pensamento é ainda mais perceptível: "[...] a mais alta paixão da inteligência consiste em querer o choque, não obstante o choque, de uma ou de outra maneira, tenha de tornar-se a sua ruína. Assim, o maior paradoxo do pensamento é querer descobrir algo que ele próprio não possa pensar". ${ }^{2}$

Dê-se atenção à expressão "maior paradoxo do pensamento", usada pelo pseudônimo kierkegaardiano Climacus no trecho citado acima. Por que seria ele maior que qualquer outro paradoxo na história da filosofia? Seria ele um "paradoxo mais paradoxal" que outros, como os de Zenão? Bom, para compreender a magnitude do paradoxo kierkegaardiano apresentado no livro de Climacus, é preciso levar em consideração uma das características fundamentais do pensamento kierkegaardiano, um aspecto que informa todos os escritos que o filósofo dinamarquês produziu em sua atividade como escritor: seu caráter religioso. Em 1851, Kierkegaard publicou um texto bastante curto, intitulado Sobre a minha atividade de escritor, no qual apresenta considerações sobre sua própria obra, de modo semelhante à obra Ponto de vista explicativo da minha obra como escritor, que Kierkegaard decidiu não publicar e que só veio a público após sua morte. No referido texto publicado em 1851, Kierkegaard afirma que tanto sua escrita poética e estética quanto sua escrita filosófica e especulativa são somente pontos de partida de um movimento que expressa, em sua totalidade, a escrita religiosa. Eis o que Kierkegaard afirmou:

Tal movimento foi percorrido ou descrito uno tenore [em um único movimento] - em um fôlego só, por assim dizer - de modo que a minha produção, considerada no seu conjunto, é religiosa do início ao fim, coisa que qualquer um que saiba ver, se quiser ver, deve também ver. [...] o entendedor reconhecerá também que a tal produção corresponde como artífice um homem que qua autor "quis uma coisa só". O entendedor reconhecerá, além do mais, que tal coisa é só o religioso [...]. ${ }^{3}$

Esta declaração que Kierkegaard fez sobre sua própria obra pode ser tomada como ponto de partida para as reflexões que ora se propõem sobre a ideia de Paradoxo Absoluto. $\mathrm{O}$ autor afirma categoricamente que sua produção é religiosa do início ao fim, e tal afirmação dá sustentação àqueles que preferem dizer que Kierkegaard é um escritor religioso, evitando entrar nas polêmicas (desnecessárias e infrutíferas, diga-se de passagem) sobre a possibilidade ou a inadequação de classificá-lo como filósofo ou literato. Mas, respeitando a opinião que o próprio Kierkegaard emite sobre si, não é inadequado chamá-lo de filósofo. Afinal, a passagem acima citada permite ao leitor

KIERKEGAARD, Søren. Migalhas filosóficas. 2.ed. Petrópolis: Vozes, 2008.

3 KIERKEGAARD, Søren. Sulla mia attività di scrittore. Pisa: Edizioni ETS, 2006. 
concluir que tanto a poesia e a estética quanto a filosofia e a especulação permeiam sua obra religiosa.

Daí, refletir sobre a ideia de Paradoxo Absoluto, especialmente da maneira como ela é desenvolvida na obra Migalhas Filosóficas, demanda apreciações sobre todas essas dimensões do texto: a literária, a filosófica e a religiosa. Quando o foco é lançado com mais intensidade sobre a dimensão filosófica e especulativa, vê-se que tal dimensão se desdobra e a análise se complexifica bastante, tanto por envolver questões ligadas a diversos âmbitos filosóficos, como a ontologia, a antropologia, a gnosiologia, a própria lógica e, sobretudo, a existência, quanto pela necessidade de articular tudo isso com o fio condutor religioso e com o estilo de comunicação literário.

Toda exposição breve da ideia de Paradoxo Absoluto no pensamento de Kierkegaard, principalmente dentro dos limites de um artigo acadêmico, não será capaz de abarcar todos os seus elementos importantes, não será capaz de reproduzir detalhadamente o argumento que Kierkegaard construiu sob o pseudônimo Climacus e nem conseguirá expor do modo exaustivo as discussões que a farta literatura secundária sobre o tema produziu. Para o propósito da reflexão comparativa entre o paradoxo kierkegaardiano e o irracional ottoniano, serão expostos tão somente alguns elementos fundamentais do problema.

O livro Migalhas Filosóficas está estruturado em cinco capítulos e um interlúdio (sem contar um curto prefácio, uma "propositio" brevíssima e uma "moral da história, à guisa de epílogo). O Interlúdio, por sua vez, é uma espécie de "intervalo" entre os capítulos IV e V, mas que tem importância fundamental para aquilo que Kierkegaard queria que seu leitor reconhecesse como absolutamente paradoxal.

No primeiro capítulo da obra, o pseudônimo Johannes Climacus propõe o que ele chama de um "projeto de pensamento", ou "experimento teórico". ${ }^{4}$ Em tal experimento teórico, Kierkegaard faz uma contraposição entre a doutrina socrático-platônica da reminiscência, na qual todo o conhecimento da verdade já está presente desde sempre na alma do ser humano, e a perspectiva cristã que, ao contrário do platonismo, compreende a alma humana como imperfeita por estar no pecado, e por depender de Deus para que a verdade lhe seja mostrada. A leitura desse primeiro capítulo já sugere ao leitor o tratamento do problema da verdade em múltiplas dimensões, porém de forma coerente, com a qual o autor mostra habilmente sua capacidade de articular com coesão esses sentidos. Se o problema do aprendizado da verdade começa a ser tratado primeiramente em seu aspecto gnosiológico, nos limites de uma teoria do conhecimento, Climacus se mostra capaz de conduzir o leitor de modo a fazê-lo perceber os limites daquele intelectualismo grego e levá-lo a pensar na ideia de verdade como algo que importa ao sujeito não somente do ponto de vista intelectual, mas também existencial e antropológico.

4 KIERKEGAARD, 2008, p. 27.

Protestantismo em Revista | São Leopoldo | v. 44, n. 01 | p. 21-33| jan./jun. 2018

Disponível em: <http:// periodicos.est.edu.br/index.php/nepp> 
E como o religioso permeia todo o texto, essa dimensão existencial e antropológica da discussão sobre a verdade tem também forte conotação soteriológica.

Kierkegaard, sob o pseudônimo Climacus, tenta conduzir o leitor àquelas proposições fundamentais do cristianismo no que diz respeito à verdade: a verdade é o próprio Deus, e que somente Deus, sendo a própria verdade, pode trazer a verdade ao ser humano. Para preservar a liberdade humana, porém, Deus não pode impor a verdade, ou seja, impor-se a si mesmo no coração do homem, e assim deve apresentar-se perante a humanidade como um igual, ou seja, como um homem. E assim, no segundo capítulo do livro de Climacus, "Deus como Mestre e salvador - um ensaio poético", 5 tem-se, sob uma forma literária, uma exposição da doutrina cristã da "kênosis", do esvaziamento divino e da encarnação do Verbo.

Mas Kierkegaard, como ele mesmo deixou claro, também faz uso da filosofia especulativa para transmitir suas ideias religiosas. O terceiro capítulo do livro de Climacus é justamente aquele intitulado "O Paradoxo Absoluto - um capricho metafísico", 6 é nesse capítulo que Climacus fala da inteligência querendo o choque e do paradoxo como um querer do pensamento, que quer descobrir o que ele mesmo não pode pensar. Mas por que ocorre o choque? Por que ocorre essa paixão do pensamento, uma paixão que também tem o sentido de sofrimento? Por que a verdade, compreendida em sua dimensão mais ampla como o próprio Deus que se fez carne e que proclamou ser Ele mesmo a Verdade, revelase ao intelecto como um paradoxo?

Enfatizando novamente o lado especulativo e filosófico de Kierkegaard nessa obra pseudonímica, o leitor pode perceber que Climacus lança-se ao enfrentamento de problemas metafísicos que, para o entendimento, para a razão humana, são insondáveis em sua inteireza, e terminam sempre em aporias. Tome-se o problema enfrentado no referido Interlúdio, por exemplo: “O passado é mais necessário do que o futuro? O possível, ao tornar-se real, tornou-se por isso mais necessário do que era?". ${ }^{7}$ Essas questões, subtítulos do Interlúdio, são um ponto de partida, ou mesmo um pretexto para levar o leitor a uma aporia fundamental no estabelecimento do Paradoxo Absoluto: a absoluta distinção entre tempo e eternidade e, consequentemente, entre o humano e o divino. Climacus inicia seu argumento referindo-se à hipótese de que o passado, por ser imutável, é necessário, ou seja, os eventos que passaram da possibilidade à realidade efetiva (ou à actualitas) deixaram de ser contingentes (como quando eram apenas possibilidades) e tornaram-se necessários. Climacus rechaça essa hipótese, apontando o fato de que a imutabilidade do passado não pode ser a mesma imutabilidade da necessidade, pois aquilo que é necessário está fora do âmbito do devir, do processo de vira-ser. O necessário é, desde sempre, fora do tempo, enquanto os eventos passados

\footnotetext{
KIERKEGAARD, 2008, p. 44.

KIERKEGAARD, 2008, p. 61.

KIERKEGAARD, 2008, p. 103.
} 
tornaram-se imutáveis justamente pela sua sujeição ao devir, expressão de sua natureza contingente.

Em linhas gerais, estão aí presentes os elementos fundamentais do Paradoxo Absoluto como Kierkegaard o estruturou. Deus é necessário, e não contingente. Deus, o Absoluto, não está na história e não se sujeita ao devir (e esse é um dos pontos tradicionalmente identificados nos estudos sobre Kierkegaard como uma de suas grandes oposições ao hegelianismo). Mas Deus se fez carne, tomou a forma de um homem em um período da história. Ora, o homem é criatura, está sujeito ao devir, vem a ser quando nasce e perece quando chegam ao fim os seus dias na temporalidade. Como pode um homem ser Deus e humano simultaneamente? Este é o Paradoxo que Climacus chama de Absoluto.

As implicações dessa ideia kierkegaardiana são várias. Do ponto de vista da pura racionalidade, o ser humano não pode conhecer Deus, e Kierkegaard assim apresenta (de um modo, quiçá, semelhante a Kant) um problema sério para aqueles que pretendem empreender uma apologética fundamentada puramente na razão. O Paradoxo Absoluto, essa "paixão do pensamento", só pode ser abraçado pelo ser humano pela fé, e não pelo conceito. E aqui se pode voltar àqueles problemas mencionados na introdução: Kierkegaard é, por isso, um propositor do irracionalismo? Estaria ele propondo que o sujeito que decide dar o salto da fé está se lançando a um absurdo que foi demonstrado como contra-racional? Mais adiante será sugerido que não, que o Paradoxo Absoluto não é, per se, contra-racional, ou uma contradição formal em si, que ele não é contra rationem, mas sim supra rationem. Antes de enfrentar essas questões mais diretamente, porém, será abordada a questão daquilo que Rudolf Otto, sete décadas depois de Kierkegaard, chamou de irracional.

\section{O irracional ottoniano}

O termo "irracional" é de importância fundamental na obra O Sagrado, de Rudolf Otto, publicada em 1917. Otto foi responsável por introduzir e consagrar na teologia, na filosofia e na ciência da religião em geral o termo "numinoso" e o próprio uso, hoje amplamente disseminado, do termo "sagrado" como um substantivo deve muito a ele. Mas não se pode esquecer que o termo "irracional" foi deliberadamente escolhido por Otto como fundamental para a transmissão de suas ideias desse seu livro mais conhecido. O irracional aparece já no próprio subtítulo da obra: “os aspectos irracionais na noção do divino e sua relação com o racional", 8 e o primeiro capítulo é justamente intitulado "racional e irracional" ${ }^{9} \mathrm{O}$ tradutor da edição brasileira referenciada neste artigo, Walter O. Schlupp, elaborou um glossário com termos importantes escolhidos por Otto para expressar várias de suas ideais no livro, e em alguns casos justificou sua escolha de tradução o português desses termos originais em alemão. Ao tratar da escolha da palavra

8 OTTO, Rudolf. O Sagrado. Petrópolis: Vozes; São Leopoldo: Sinodal, 2007, p. 1.

9 OTTO, 2007, p. 33. 
"irracional" para traduzir o original alemão "irrational", o referido tradutor fez uma crítica bastante acertada daquelas traduções, como a para a língua inglesa, que fazem uma "interpretação eufêmica"10 do irracional e usam expressões como "não-racional". Segundo o tradutor brasileiro:

O uso exclusivo de non-rational, "não-racional", na versão inglesa, parecenos uma interpretação eufêmica, atenuante e racionalizante, que não faz justiça a caracterizações dadas ao irracional do numinoso como: antinômico, mirum = espantoso, paradoxon, tremendum, einfernd $=$ irado, que chega a provocar deima panikón = pânico apavorado [...].11

Otto, como afirmado acima, decidiu tratar da relação entre o racional e o irracional já no primeiro capítulo de O Sagrado. O racional, para Otto, é o que se liga ao conceito, à possibilidade de definição clara da divindade:

Para toda e qualquer ideia teísta de Deus, sobretudo para a cristã, é essencial que ela defina a divindade com clareza, caracterizando-a com atributos como espírito, razão, vontade, intenção, boa vontade, onipotência, unidade da essência, consciência e similares, e que ela portanto seja pensada como correspondendo ao aspecto pessoal-racional, como o ser humano o percebe em si próprio de forma limitada e inibida. No divino, todos esses atributos são pensados como sendo "absolutos", ou seja, como "perfeitos". Trata-se, no caso, de conceitos claros e nítidos, acessíveis à análise pensante, podendo inclusive ser definidos. Se chamarmos de racional um objeto que pode ser pensado com clareza conceitual, deve-se caracterizar como racional a essência da divindade descrita nesses atributos..$^{12}$

Com isso, os aspectos racionais da noção do divino não são negados por Otto; ao contrário, ele faz questão de afirmá-los logo no início de sua obra. A religião (e especialmente a religião cristã para $\mathrm{Otto}^{13}$ ) possui conceitos claros. É pertinente aqui fazer referência a outra obra de Otto, publicada antes de O Sagrado. Em A filosofia da Religião baseada em Kant e Fries, publicada em 1909, Otto afirma claramente que "toda religião elabora para si uma metafísica primitiva"14 e que "em toda religião, esses conceitos [divindade, Absoluto, alma] são metafísicos no mais alto sentido" ${ }^{15}$

Uma das ideias centrais no pensamento de Otto, especialmente desenvolvida no livro O Sagrado, é a de que aquilo que ele denomina "sagrado" é uma categoria, em sentido análogo ao kantiano, mas uma categoria composta de racional e irracional. Vê-se,

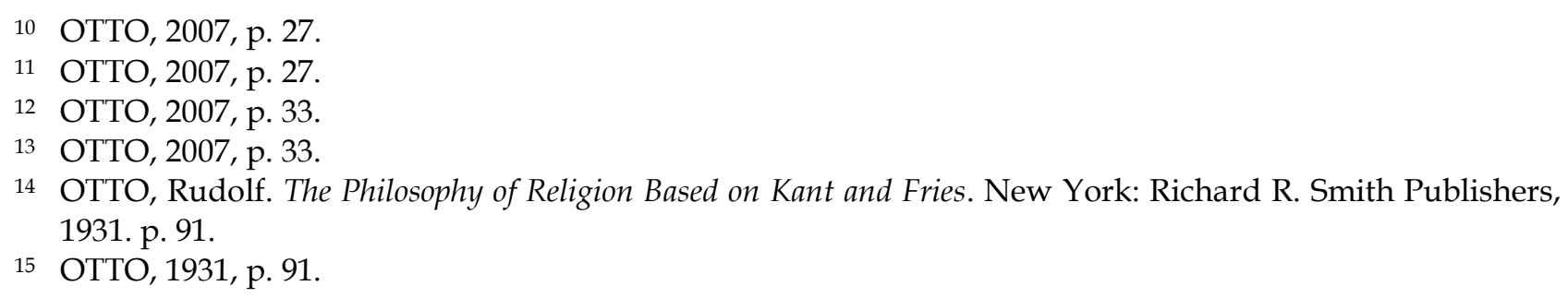

14 OTTO, Rudolf. The Philosophy of Religion Based on Kant and Fries. New York: Richard R. Smith Publishers, 1931. p. 91.

15 OTTO, 1931, p. 91. 
pelas passagens citadas acima, além de vários outros argumentos desenvolvidos nas duas referidas obras, que Otto não descuida da exposição daquilo que ele percebe como o elemento racional presente na religião e na religiosidade humana. Mas Otto tornou-se célebre justamente por evitar lançar seu foco, no estudo da religião, exclusivamente sobre a ideia de Deus (que não é, de modo algum, negligenciada em suas obras) e dar atenção inédita à experiência religiosa, e à experiência como elemento fundante da religião.

Para Otto, o racional, portanto, está presente em toda religião, como exemplificado pelas passagens citadas acima. Mas as elaborações racionais encontradas nas tradições religiosas (às quais Otto se refere frequentemente como "metafísica” em sua obra de 1909) são um elemento posterior à experiência do numinoso, e é em tal experiência, caracterizada por uma intuição [Ahnung], que se encontra o irracional. O racional, a racionalização, é um momento posterior à experiência religiosa ${ }^{16}$ quando Otto reflete sobre a origem da religião, ainda que os elementos racionais mantenham-se em relação com o conteúdo da experiência religiosa fundante ao longo da história da religião. E como explica Otto, há uma interrelação essencial entre o racional e o irracional na religião. Ao falar sobre seu conceito de "esquematização", Otto aborda o tema da "relação do racional com o irracional na ideia complexo do sagrado",17 compreendida como "uma categoriacomplexo plena e consumada do próprio sagrado em seu sentido complexo" ${ }^{18}$

Mas o que exatamente Otto quer dizer com o termo "irracional" em sua contraposição ao racional? Ele deixa claro, em mais de um de seus escritos, que a experiência religiosa tem algo que não pode ser alcançado pela razão, mas isso não livra o leitor da possibilidade de interpretações diversas sobre o termo "irracional". Otto teve o cuidado de especificar o uso do termo em seu livro, sabendo exatamente dessa possibilidade:

Lidar com esse termo hoje virou uma espécie de esporte. Busca-se o irracional nas mais diferentes áreas. Geralmente as pessoas se poupam do esforço de indicar precisamente o que querem dizer com isso, não raro dando-lhe sentidos os mais diferentes possíveis, ou utilizando-o desleixadamente em termos tão vagos, que os possíveis sentidos são os mais diversos [...] Quem usa o termo hoje me dia tem a obrigação de dizer em que sentido o faz. [...] Por "irracional" não entendemos o vago, o néscio, ainda não submetido à razão, nem a birra das pulsões individuais ou das engrenagens do mundo contra a racionalização. Usamos aquele linguajar presente, por exemplo, ao se dizer de um evento um tanto singular, que por sua profundidade foge à interpretação inteligente: "isto tem algo de irracional". Por "racional" na ideia do divino entendemos aquilo que nela pode ser formulado com clareza, compreendido com conceitos familiares e definíveis. Afirmamos então que ao redor desse âmbito de clareza conceitual existe uma esfera misteriosa e obscura que foge não ao nosso

16 OTTO, 2007, p. 58-59.

17 OTTO, 2007, p. 86.

18 OTTO, 2007, p. 86.

Protestantismo em Revista | São Leopoldo | v. 44, n. 01 | p. 21-33| jan./jun. 2018

Disponível em: <http://periodicos.est.edu.br/index.php/nepp> 
sentir, mas ao nosso pensar conceitual, e que por isso chamamos de "irracional". ${ }^{19}$

Aqui, então, é possível enxergar uma forte proximidade entre o que Otto chama de irracional e o que Kierkegaard chama de paradoxo. Há um âmbito em que há clareza conceitual, acessível à racionalidade, um trecho em uma estrada que pode ser percorrido pelo entendimento humano na companhia da razão, mas há um ponto nessa estrada que a razão parece não poder ultrapassar, e que a partir desse ponto o ser humano deve prosseguir sem ela, acompanhado por sentimento [Gefühl], ou intuição [Ahnung] ou pela paixão. Mas é justamente esse modo de compreensão dos limites da razão que costuma gerar polêmicas envolvendo interpretações de ambos os autores como irracionalistas, como se, em última análise, fossem o tipo de autor que propõe um abandono da razão de modo generalizado.

\section{A razão é contrariada ou ultrapassada?}

Falando de um modo bastante simples e generalizante, é possível dizer que aquilo que é racional também é passível de comunicação por meio da linguagem, de descrições, de exposições, explanações, argumentos. Quando se trata do uso que Kierkegaard e Otto fazem de exposições racionais em suas obras, o leitor é capaz de perceber que a razão, sem dúvida, desempenha um papel importante na exposição das ideias desses dois autores. No caso de Kierkegaard, há que se levar em conta as peculiaridades de seu estilo literário, de sua ideia de comunicar-se indiretamente com seus leitores, não fazendo exposições ao estilo dos professores de sua época (ou fazendo-o de modo irônico, como no caso do livro $O$ conceito de angústia). Em contraposição a Kierkegaard, pode-se dizer que Otto se comunica diretamente, fazendo explanações de suas ideias sem ter a pretensão de usar recursos poético-literários, ainda que haja diversos exemplos de poesia religiosa em $O$ Sagrado. Mas em ambos o leitor atento perceberá seguramente que uma exposição racional, uma comunicação de ideias passíveis de transmissão por meio de um discurso acessível ao entendimento, está presente.

No caso de Otto, não há muito que se discutir sobre o a importância que ele próprio dá ao papel da razão na religião, e críticas dirigidas a ele considerando-o um irracionalista são, muito provavelmente, fruto de leituras superficiais de seus textos ou de leituras superficiais de comentaristas e da literatura secundária em geral. Não obstante, como observou Robert Streetman, contra Otto surgiram "várias acusações de irracionalismo, subjetivismo e psicologismo" ${ }^{20}$ No caso de Kierkegaard, o já mencionado recurso da comunicação indireta, o uso de pseudônimos representando perspectivas diferentes, a perceptível mudança de estilo de escrita entre um pseudônimo e outro,

19 OTTO, 2007, p. 97-98.

20 STREETMAN, Robert. Some Later Thoughts of Otto on the Holy. Journal of the American Academy of Religion, v. 48, n. 3, Oxford University Press, p. 365-384, 1980. p. 367. 
podem tornar a interpretação de seus escritos mais suscetíveis de divergências e polêmicas e, consequentemente, ao tipo de acusação que foi dirigido a Otto.

Kierkegaard via a si próprio como alguém incumbido de desempenhar uma tarefa, que consistia em tornar as pessoas atentas ao cristianismo. Em seu livro póstumo Ponto de vista explicativo da minha obra como escritor, o filósofo dinamarquês faz a seguinte afirmação:

Um homem pode ter a sorte de fazer muito por outro, a de o conduzir até onde deseja levá-lo; para nos atermos ao nosso tema principal e constante, pode ter a felicidade de o ajudar a tornar-se cristão. Mas esta possibilidade não está em meu poder; depende de uma multidão de circunstâncias e, sobretudo, da vontade do outro. Nunca posso de modo algum impor a alguém uma opinião, uma conviç̧ão, uma crença; mas posso uma coisa, num sentido a primeira (porque ela condiciona a seguinte: a aceitação da opinião, da convicção, da crença), e num outro, a última, se não quer a continuação: posso obrigá-lo a tornar-se atento. ${ }^{21}$

Kierkegaard entendia que não podia transmitir a outra pessoa as suas próprias convicções e crenças, mas podia torná-las atentas. Nessa tarefa de tornar alguém atento à verdade, não há como negar que é feito o uso da razão, do discurso racional, da comunicação de ideias passíveis de exposição por um sujeito e de intelecção por outro. $\mathrm{O}$ mesmo se dá com Otto. Como afirmado em um trabalho anterior que analisa comparativamente Kierkegaard e Otto, o pensador alemão “admite a possibilidade de se conduzir alguém a um ponto onde o sujeito estará exposto à eclosão do objeto numinoso em sua psique". ${ }^{22}$ Mas aquilo que é irracional ou paradoxal não pode ser transmitido do mesmo modo como um sujeito transmite a outro uma informação inteligível, situada dentro dos limites da pura racionalidade. O irracional e o paradoxo são experienciados pelo sujeito, mas não comunicados.

Neste ponto, porém, é possível surgir uma questão legítima, que se diferencia das acusações simplórias dirigidas aos autores, de que são irracionalistas em um sentido amplo e generalizante. É certo que, para ambos, a razão pode levar o sujeito até certo ponto, a partir do qual o sujeito se deparará com o irracional ou com o paradoxo. É certo que o irracional e o paradoxo são inacessíveis à razão da qual o ser humano é dotado. Mas seria o paradoxo kierkegaardiano e o irracional ottoniano, considerados em si mesmos, contrários à razão? Ou seriam eles apenas a expressão de um âmbito inalcançável para razão humana, mas não irracionais em si mesmos? Tomando-se como referência o pensamento cristão, o paradoxo, sendo a própria verdade, e sendo o próprio Deus, é paradoxal ou irracional para si mesmo?

21 KIERKEGAARD, Søren. Ponto de vista explicativo da minha obra como escritor. Lisboa: Edições 70, 1986, p. 45.

22 QUAGLIO DE SOUZA, 2014, p. 57. Ver também OTTO, 2007, p. 85. 
Jonas Roos, em sua obra Tornar-se Cristão: O Paradoxo Absoluto e a existência sob juizo e graça em Søren Kierkegaard, faz uma exposição da disputa sobre esta questão entre pesquisadores da obra de Kierkegaard. Segundo Roos, que cita Heywood Thomas, determinar se o paradoxo é contra rationem ou supra rationem é uma das preocupações dos estudiosos do pensador dinamarquês. ${ }^{23}$ Segundo autores como Alaistair Hannay, o paradoxo em Kierkegaard é contrário à razão, e representaria uma contradição formal em termos lógicos. Ele seria, portanto, irracional em si e para si. Já autores como C. S. Evans defendem a posição de que o paradoxo em Kierkegaard é suprarracional, ou seja, ele se apresenta diante das limitações da razão humana como um paradoxo, e como irracional, mas não é em si e para si irracional ou paradoxal. Conforme afirma Roos, "tanto numa acepção quanto noutra, fica claro que o paradoxo não pode ser compreendido pela razão. [...] pode-se enquadrar o paradoxo aqui como o sistematicamente incompreensivel" ${ }^{24} \mathrm{~A}$ própria ideia de um sistema, porém, é vista com muita desconfiança por Kierkegaard. O paradoxo se põe diante do ser humano justamente porque ele não pode ter uma visão sistemática que signifique uma compreensão da totalidade da realidade, da sua completude. E o mesmo argumento pode ser perfeitamente estendido à ideia de irracional em Otto.

É curioso notar que Otto, mesmo afirmando (como citado acima) que o irracional é aquilo que foge ao nosso pensar conceitual, mas não ao nosso sentir, aborda também um problema idêntico a esse encontrado nos estudos de Kierkegaard. Em O Sagrado, ao discutir o aspecto de misterium tremendum do numinoso, Otto fala de três níveis do caráter de mirum, o ligado ao mistério e ao miraculoso do numinoso: a simples estranheza, o paradoxal e o antinômico. ${ }^{25}$ É curioso que, nessa parte da obra, Otto sugere a possibilidade de compreensão do irracional como paradoxal e antinômico em um sentido que se aproxima da interpretação contra rationem dos estudos kierkegaardianos citada acima. Conforme diz Otto:

Enquanto totalmente outro, o mirum é (a) primeiramente o incompreensível e inconcebível, [...] aquilo que foge ao nosso "entendimento" na medida em que "transcende (nossas) categorias". (b) Além de ultrapassá-las, ele ocasionalmente parece contrapor-se a elas, anulá-las e confundi-las. Então deixa de ser apenas incompreensível e chega a ser paradoxal; encontra-se então não apenas acima de toda e qualquer razão, mas parece "contrariar a razão". (c) E mais: sua forma mais radical é então o que chamamos de antinômica. Isto é mais do que meramente paradoxal. Aí parecem resultar não só afirmações contrárias à razão, a seus critérios e às suas leis, mas que ainda se bifurcam e enunciam opostos a respeito do seu objeto, contradições incompatíveis e insolúveis.

23 ROOS, Jonas. Tornar-se Cristão: O Paradoxo Absoluto e a existência sob juízo e graça em Søren Kierkegaard. Tese (Doutorado em Teologia) EST, São Leopoldo, 2007. p. 118-123.

24 ROOS, 2007, p. 119.

25 OTTO, 2007, p. 62. 
Aí, ante a tentativa de se entender racionalmente, o mirum apresenta-se em sua forma irracional mais exacerbada: não só inacessível a nossas categorias por causa de sua alteridade (dissimilitas), nem apenas confundindo, ofuscando e amedrontando e afligindo a razão, mas em oposição a si próprio, em contraposição e contradição. ${ }^{26}$

Como dito acima, Otto parece aqui aproximar-se da interpretação de que o irracional é irracional em si e para si, como na interpretação contra rationem do paradoxo kierkegaardiano. Contudo, algumas observações devem ser feitas. Em primeiro lugar, Otto relaciona esses níveis mais profundos do irracional, o paradoxal e o antinômico, com aquilo que ele chama de "teologia mística" que se caracteriza pela "exacerbação irracional na ideia de Deus". ${ }^{27}$ Em segundo lugar, é perceptível que Otto faz referência ao modo como o numinoso é percebido, ou sentido, ou intuído pelo sujeito. Mas em nenhum momento Otto expressa a pretensão de que seria possível ao ser humano assumir a posição do divino para poder afirmar essa pretensa irracionalidade intrínseca do numinoso. Não há, neste argumento de Otto, uma afirmação da capacidade de se determinar se esse irracional é assim antinômico de fato. Afinal, o primeiro passo descrito por Otto não é justamente uma ultrapassagem do nosso entendimento pelo mirum? É certo que nesta passagem Otto parece se aproximar da interpretação contra rationem dos kierkegaardianos. Mas há um contexto específico em discussão, de uma tradição mística não representativa de todo o fenômeno religioso, e que não parece ser passível de ser estendido à religião em geral tal como Otto a aborda.

\section{Considerações finais}

O problema é eminentemente insolúvel. Afinal, se o irracional ou o paradoxo por definição ultrapassam a razão, não será possível jamais demonstrar sua natureza contra racional ou supra racional. Mas talvez, um bom caminho para se abordar esse problema seja refletir sobre a própria definição de paradoxo. Em seu dicionário de filosofia, Simon Blackburn fala do paradoxo nos seguintes termos:

Um paradoxo surge quando um conjunto de premissas aparentemente inquestionáveis origina conclusões inaceitáveis ou contraditórias. A resolução de um paradoxo implica mostrar que há um erro escondido nas premissas, ou que o raciocínio é incorreto, ou que a conclusão aparentemente inaceitável pode, afinal, ser tolerada. Os paradoxos desempenham, portanto, um papel importante na filosofia, visto que a existência de um paradoxo não-resolvido mostra que há algo nos nossos raciocínios ou nos nossos conceitos que não compreendemos. ${ }^{28}$

26 OTTO, 2007, p. 62.

27 OTTO, 2007, p. 62.

28 BLACKBURN, Simon. Dicionário Oxford de filosofia. Rio de Janeiro: Zahar, 1997. p. 279-280. 
Um ponto parece ter ficado claro: Otto e Kierkegaard afirmam limites para o entendimento, e situam o irracional e o paradoxo para além desses limites. Assim, levando-se em consideração a definição de paradoxo dada acima, não é possível descartar quando se aborda o problema do paradoxo ou do irracional, a possibilidade de que haja "algo nos nossos raciocínios ou nos nossos conceitos que não compreendemos", mas que seria compreensível, e percebido como plenamente racional e não contraditório, para a divindade, para a ratio aeterna.

\section{Referências}

BLACKBURN, Simon. Dicionário Oxford de filosofia. Rio de Janeiro: Zahar, 1997.

KIERKEGAARD, Søren. Ponto de vista explicativo da minha obra como escritor. Lisboa: Edições 70, 1986. . Sulla mia attività di scrittore. Pisa: Edizioni ETS, 2006. . Migalhas filosóficas. 2. ed. Petrópolis: Vozes, 2008.

OTTO, Rudolf. The Philosophy of Religion Based on Kant and Fries. New York: Richard R. Smith Publishers, 1931.

O Sagrado. Petrópolis: Vozes; São Leopoldo: Sinodal, 2007.

QUAGLIO DE SOUZA, Humberto Araujo. Kierkegaard sob a perspectiva de Otto: o instante e o numinoso. Revista Pandora Brasil, n. 23, p. 25-36, out. 2010. Ars, 2014.

. Fenomenologia da experiência religiosa em Kierkegaard e Rudolf Otto. São Paulo: Liber

ROOS, Jonas. Tornar-se Cristão: O Paradoxo Absoluto e a existência sob juízo e graça em Søren Kierkegaard. Tese (Doutorado em Teologia) EST, São Leopoldo, 2007.

STREETMAN, Robert. Some Later Thoughts of Otto on the Holy. Journal of the American Academy of Religion, v. 48, n. 3, Oxford University Press, p. 365-384, 1980. 